TOWARD A NEW HUMANISM

\title{
One world anthropology
}

\author{
Tim Ingold, University of Aberdeen
}

Anthropology is a philosophical inquiry into the conditions and possibilities of life in the one world we all inhabit. That this world is indeed one is a core principle of the discipline. By exploring the relation between the particular life and life-as-a-whole, I show how the latter can be understood as a correspondence in which lives are not added together but carry on alongside one another. Life itself, then, is not the summation but the correspondence of its particulars. Comparing ideas of the self and the soul, founded respectively in regimes of naturalism and animism, I show how correspondence proceeds through a process of interstitial differentiation, in which agency is inside action rather than in front of it. This calls for a "turn" that is not ontological but ontogenetic, leading us to conceive of the one world as neither a universe nor a fractiverse but as a pluriverse.

Keywords: animism, correspondence, difference, Inuit, life, ontogenesis, pluriverse, soul

Having received all mortal and immortal creatures and being therewithal replenished, this universe hath thus come into being, living and visible, containing all things that are visible, the image of its maker, a god perceptible, most mighty and good, most fair and perfect, even this one and only-begotten world that is.

-Plato, The Timaeus (Archer-Hind 1888, 345)

\section{The singular and the plural}

Many years ago, I came up with my own definition of anthropology. It was "philosophy with the people in" (Ingold 1992: 696). By this I meant two things. Firstly, the questions that anthropology asks are indeed philosophical ones: they are questions about what it means to be, to know, to think, imagine, perceive, act, remember, learn, live in the company of others, administer justice, exercise power, relate to the environment, confront our own mortality, and so on and so forth. These questions are endless. But secondly, the way anthropology does its philosophizing is primarily through its engagements - in both observation and conversationwith the people among whom we work. Indeed, I would now go further, to include not just the people but all the other beings, of manifold kinds, with whom or which we share our lives. There is here an implied criticism of philosophical philosophers who would rather shy away from any such engagement, preferring to labor in the library with their canonical texts. We anthropologists, I contend, can do philosophy better, by virtue of bringing into the conversation the voices, the experi- ence, and the wisdom of countless human beingsnot to mention legions of nonhumans - which would otherwise be excluded. To do this kind of philosophy is, in effect, to make a conversation of life itself.

This conversation - this life - is not, however, just about the world. In an important sense which I shall elaborate, it is the world. To join the conversation, then, is to inhabit the world. That the inhabited world is indeed one is, in my view, a core principle of our discipline. It is a principle that we neglect at our peril. I am afraid that in practice, it has all too readily been neglected, along with the challenges and responsibilities it entails, in favor of a facile appeal to plurality. It sometimes seems that anthropologists are constitutionally averse to oneness, to singularity, and likewise obsessed with the plural. Never one world; always many worlds. Once these were the many worlds of symbolic culture; now, in the wake of the so-called "ontological turn," we have the many worlds of essential being, of realities to be symbolized. Everyone and everything, it seems, is its own world. You name it, and there's a world for you.

HAU: Journal of Ethnographic Theory. Volume 8, number 1/2. DOI: http://dx.doi.org/10.1086/698315

(C) The Society for Ethnographic Theory. All rights reserved. 2575-1433/2018/0812-0019\$10.00 
But what do we mean by plurality? And in what sense is it opposed to singularity? The question of how to reconcile the singular and the plural—or in slightly different terms, the universal and the particular - could well turn out to be the central problem of a truly philosophical anthropology.

Let me offer an example. People indigenous to the High Arctic, mainly of northernmost Canada and Greenland, know themselves and are known as Inuit. The word is a plural form, derived from the singular inuk, which roughly translates as "soul." In a modern idiom we might suppose that every soul belongs to an individual, and therefore that the plural Inuit simply denotes a population of individuals. Greenland and Canada, we say, have their respective Inuit populations. We could do a census and count them up. But for the people themselves, at least traditionally, souls could not be counted or enumerated in this way. As the ethnographer Henry Stewart has noted, the plural form is "most certainly not a collective designation for all original inhabitants of the tundra Arctic." It rather connotes something like "autonomous existence" (Stewart 2002: 90). Most often the plural suffix (-miut) followed a toponym or place-marker - as, for example, Netsilik, plural Netsilingmiut, or Iglulik, plural Iglulingmiut - and could be glossed as "soul-life going on in and around this place." The question this raises, then, is of how to get from one to the other, from the life of the soul (inuk) to soul-life (inuit). Not by multiplication: or not at least in the arithmetic sense familiar to us from elementary school. Nor, conversely, can you get from soul-life to the life of the soul by division. Call the plural a multiplicity if you must, but do not suppose it is a multiplication of the singular!

\section{Wholes and parts}

The soul, after all, is not an entity sunk inexorably into itself. That is to say, it is not an object, in the sense recently promulgated by the advocates of so-called "objectoriented ontology" (see, for example, Harman 2011). In their view, everything you might care to name has its own inscrutable essence, neither reducible to the more elementary particles of which it and other entities might be constituted, nor soluble into constructs at some superordinate level of existence. Admittedly, the soul is amenable neither to reduction nor to totalization; neither to "undermining" nor to "overmining," as the object-oriented philosophers would put it (Harman 2011: 172). But this does not make the soul an object-in-itself. It is, more funda- mentally, a movement, which takes the grammatical form not of the noun or pronoun, but of the verb. And the most outstanding characteristic of this movement is that it carries on, or keeps on going. For Inuit people, it even carries on over generations, as a grandchild, for example, is animated by the soul of its grandparent, leading parents to address their children, sometimes, as they would address their own parents, and to treat them with equivalent deference and respect (Nuttall 1994). The idea of "early years," as though children were closer to some imaginary point of origin in a process of socialization, therefore makes no sense. Everyone, at any moment, is both older and younger than themselves.

Thus souls - or lives - are movements, and to echo the celebrated aphorism of Heraclitus, one cannot step twice into the life of the same soul. What, then, is the relation between the life of the soul and soul-life, or to put it in more general terms, between the particular life and life itself? Is it a relation of part to whole? Yes, so long as we don't make the common mistake of confusing wholeness with totalization (Ingold 2007: 209). Totality, to my ear at least, implies addition and completion: whether or not you consider the result to be more than, equal to, or even less than the sum of its parts, the logic of summation remains. "Life as a whole," however, cannot be reached by any procedure of summation, whether additive or multiplicative. It is never complete, nor is it even on the way to completion, since it advances to no end save its own continuation. As the generative potential of a world in becoming, life is always going on, a perpetual origination. Or as one elder from among the Wemindji Cree of northern Canada told the ethnographer Colin Scott, life is "continuous birth" (Scott 1989: 195).

Particular lives, too, can be parts of life-as-a-wholethe life of the soul a part of soul-life - but only so long as we think of these parts, likewise, as ways of carrying on, like the lines of a composition. The idea of composition, according to philosopher Bruno Latour (2010: 473-4), "underlines that things have to be put together (Latin componere) while retaining their heterogeneity." Thus, parts remain differentiable within the whole; they do not merge into one homogeneous current of vitality. In all other respects, however, the sense in which I speak of composition is entirely contrary to Latour's. For him it is a medley of bits and pieces, "utterly heterogeneous," which can at best make up a composite material that is "fragile, revisable and diverse." Such a composite can be as readily decomposed as composed (Latour 2010: 474). The analogy I have in mind, by contrast, is that 
of polyphonic music, in which every voice, or every instrument, carries on along its own melodic line. In music the relation between parts and whole is not summativeneither additive nor multiplicative-but contrapuntal. Think of the tenor part in the chorus or the cello part in the symphony. I want to think of the life of every particular soul, likewise, as a line of counterpoint that, even as it issues forth, is continually attentive and responsive to each and every other. Souls, we might say, are answerable to one another, a condition that carries entailments of both responsiveness and responsibility (Wentzer 2014).

\section{Assemblage and correspondence}

Precisely because souls go along together and because their continual regeneration is nourished and impelled by the memory of their association, soul-life is a whole that cannot be decomposed without causing grief if not destruction to the lives of its parts. This is why I am disinclined to think of the composition as an assembly, or "assemblage" as it is ubiquitously rendered through awkward translation from the French. The source for this translation commonly turns out to lie in the sprawling meditations of philosopher Gilles Deleuze and his collaborator, psychoanalyst Félix Guattari, in A thousand plateaus (Mille plateaux), of which more below. The difficulties of translating this work are indeed formidable, and it is true that some of the plethora of senses that have clustered around "assemblage," as something like a gathering or bundling of life-lines reminiscent of sheaves of corn at harvest, do approximate to what I have in mind (Ingold 1993: 168). But others most definitely do not. An example is philosopher Manuel De Landa's appropriation of the term to denote a transitory and contingent coming together of heterogeneous components that cohere only through an exterior contact or adhesion that leaves their inner natures more or less unaffected, and that can therefore be detached and reconfigured in other arrangements without loss (DeLanda 2006: 18). This, to my mind, is precisely how not to describe the way that particular lives play into life itself. The trouble is that by resorting to the notion of assemblage as a catch-all, it is all too easy to obscure or gloss over a distinction that I consider to be of capital importance.

This is the distinction between the kinds of work done in language with the little words "and" and "with." The logic of the conjunction is articulatory; that of the preposition differential. Contrasting the figures of the tree and the rhizome, Deleuze and Guattari allow them to stand, respectively, for filiation and alliance. The Deleuzoguattarian multiplicity is unashamedly rhizomatic rather than dendritic. And the rhizome, they say, is nothing but alliance. "The tree imposes the verb 'to be', but the fabric of the rhizome is the conjunction, 'and ... and . . and ...'" (Deleuze and Guattari 2004: 27). With respect, this is grossly unfair to living trees which, unlike their diagrammatic counterparts, grow, branch, and swerve from within the midst of things every bit as much as do the tangling roots of the rhizome. In the sphere of human relations, though filiation might be marked on the anthropologist's genealogical chart as a line connecting two points, standing respectively for parent and child, in real life it is a process of becoming in the course of which, through "growing older together" (Schutz 1962:17), the child carries on the life of its parent while progressively differentiating its own life from that which it engendered it. Filiation is not the connection of parent and child, it the life of parent with child (Figure 1). Just as in musical counterpoint, parts are not components that are added to one another but movements that carry on alongside one another, so too, in the human family, lives lived in counterpoint are not "and ... and ... and" but "with . .. with . . . with." And in answering - or responding - to one another, they co-respond. Thus, in place of the assemblage as a way of talking about the multiplicity of soul-life, as if it were an alliance of souls, I propose the term correspondence to connote their affiliation. "Life as a whole," then, is not the articulatory summation but the differential correspondence of its particulars (Ingold 2015: 23).

It follows that the relations that make up the whole are not between but along. Between-ness gives us the idea of interaction, a reciprocal back-and-forth exchange between subject positions. The along-ness of correspondence, by contrast, does not go back and forth but side by side, like companions walking together or playing music together. And the thing about walking and playing is that they do not issue from a position but continually pull the performer out of it. Both, as the philosopher of education Jan Masschelein puts it, are practices of exposure (Masschelein 2010: 278). The English language has a beautiful word, longing, to describe the exposure of going along. In longing, an imagination that lies beyond the horizon of conceptualization loops proleptically back to meet an origination that lies beyond the reach of memory, as in the cycling soul-life of the Inuit, in a place where past and future merge. It is a place we perpetually dream of and strive for, but never reach. 


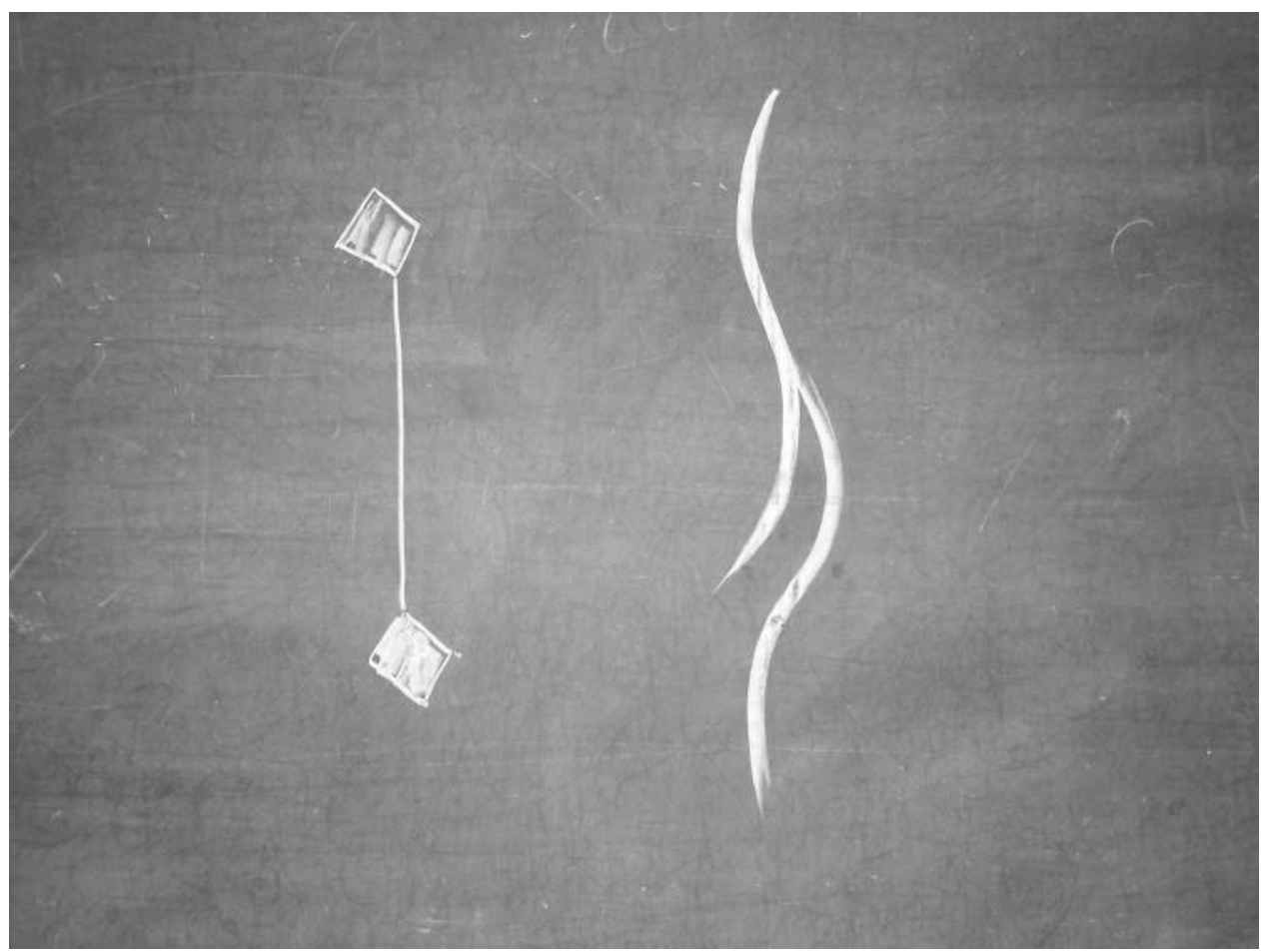

Figure 1: Filiation. Left: The connection of parent and child, as it might be drawn on a genealogical chart. Right: The life of parent with child, as a "growing older" together.

In a workshop held at the University of Aberdeen, some three years ago, the mathematician Ricardo Nemirovsky gave us a wonderful demonstration of what this means in practice. In a nearby park, we laid out a rope in the exact form of a parabola, its ends diverging to infinity - or rather to where our rope ran out. We then viewed the parabola through a vertical sheet of Perspex and drew the line of the rope on the perspex with a felt pen. We found that we had drawn an ellipse. At infinity, the ends of the parabola had closed up. In its very open-endedness, the whole, it seems, is spatiotemporally self-encompassing: we live on the inside of eternity, as Australian Aboriginal people have long been trying to tell us with their ontology of the Dreaming or "everywhen" (Stanner 1965). With this demonstration in mind, let me return to the problem of universality. What can it mean to say of the one world that it is universal? And how does it relate to the particular, or to the relativity of the particular moment, the particular life, the way of the soul?

\section{Differentiation and diversity}

It means that we have to think of difference in terms of differentiation rather than diversity. The distinction is critical. One way to get at it is to reflect upon the meaning of the ground. How often have we heard it said that cultural particulars are superimposed upon the ground of universal human nature? Well then, what is the ground? Is it - as the founder of ecological psychology, James Gibson (1979), once put it - an underlying surface of support upon which all else rests? Or is it rather-to follow the thinking of Tadashi Suzuki (1986), one of the foremost figures of contemporary Japanese theatre-a source of growth and nourishment?

For Gibson, the ground is but a platform, affording nothing to its inhabitants save that it is "stand-on-able" (Gibson 1979: 127). To be habitable, any environment must be furnished with objects, much as an interior room must be furnished if the householder is to do more than stand in it. As chairs, tables and cupboards are set upon the floor of the room, Gibson explains, so hills, trees, and boulders are set upon the ground. As such, the ground appears as a plane of indifference, a tabula rasa, from which all variations have been excised, only to be re-imposed, as diverse, free-standing entities, upon it. For Suzuki, quite to the contrary, the ground is the very source of emergent difference. It gives rise to the features we see, the formations of the landscape, trees and buildings, even people. The floor- 
boards of the traditional Japanese house, Suzuki (1986: 21) tells us, virtually grow into the inhabitants who walk them, just as did the trees from which the boards were made once grow from the earth. Here, the ground is no more indifferent to the trees than are floorboards to people; rather, trees and people arise from the earth and from boards, respectively, in an ongoing process of differentiation (Figure 2).

The distinction I want to emphasize here is between the ground of indifference and the ground of differentiation, or - if you will - between the respective grounds of being and becoming. Being different, that is diversity; becoming different, that is differentiation. Differentiation turns to diversity by way of the twin operations of excision and reimposition: where the former cuts things out from the processes of their generation, the latter deposits them, as ready formed particulars, upon the universal ground of indifference. This ground, as we are inclined to say, is hard, providing a solid but inert foundation for the objects that rest upon it, and the activities that are conducted across its surface. It is worth noting that exactly the same metaphor is imported into our thinking about the human mind, when neuropsychologists, for example, speak of the mind's "hardware" as offering a neural substrate capable of supporting var- ious kinds of cognitive operations, including those involved in speech and manual tool-use. In the very division between the hardware and the software it supports, the separation of knowing from being, of sapiens from Homo, is replicated and reinforced. What would happen, then, if to the contrary, we were to think of the ground of human perception and cognition, or of sentience and sensibility, as something more like the floorboards of a traditional Japanese house, or, with Deleuze and Guattari (2004: 17), like a field of long grass, or even like the earth itself?

To think of difference in terms of differentiation rather than diversity is to imagine the universal not as a featureless ground upon which all variation is deposited but as a surface that is as folded and crumpled as the earth beneath our feet. With the logic of diversity, of excision and reimposition, all difference is bilateral: as features are distinguished from the ground, by way of their excision, so the ground is distinguished from the features that are then reimposed upon it. But as Deleuze sets out to show in his book on Difference and repetition (1994), in becoming different, one thing may distinguish itself from another without the latter's distinguishing itself from the former. Imagine lifting a sheet to form a crease; we register the line of the crease, we see it as

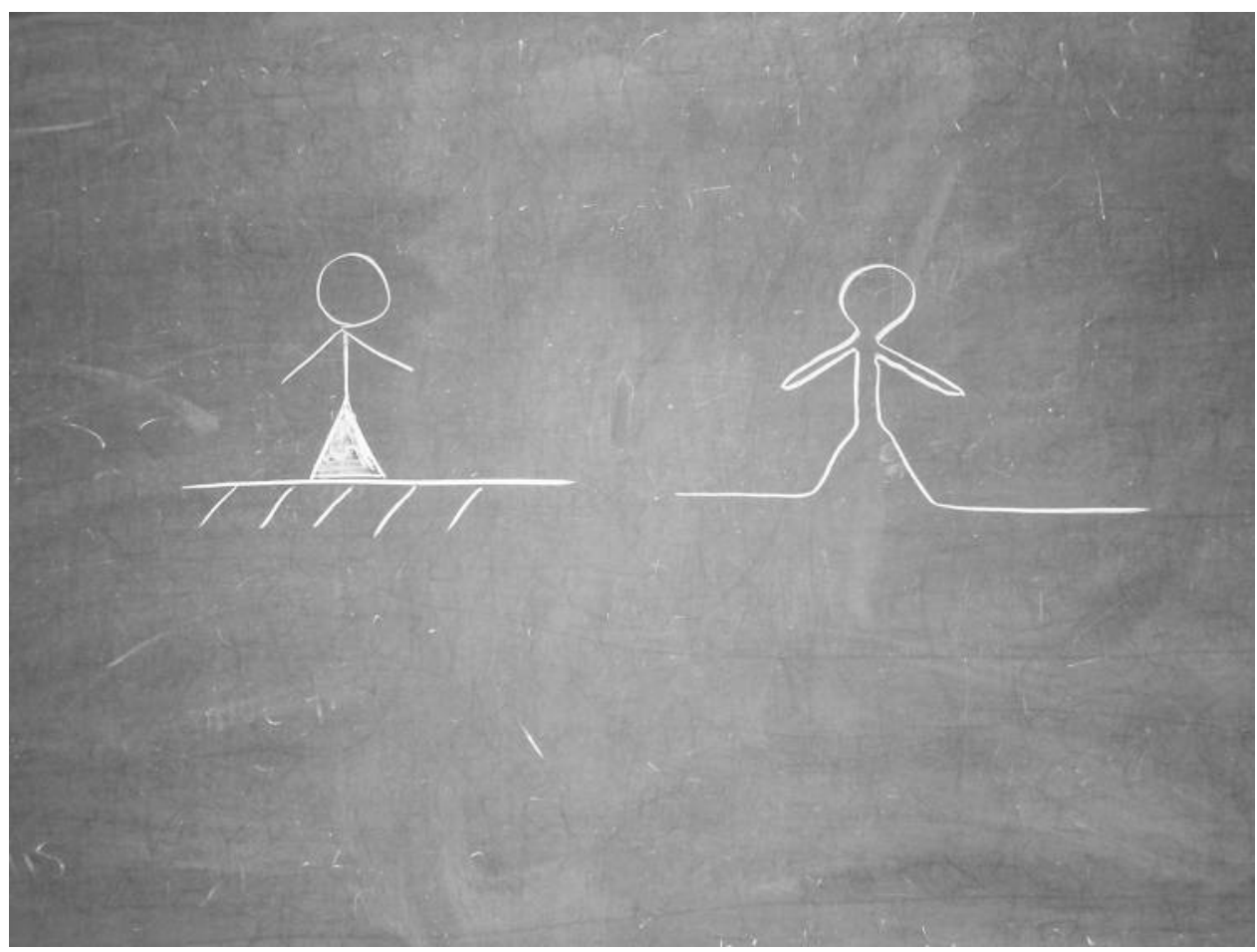

Figure 2: Figure and ground. Left: The figure is mounted on the ground of indifference. Right: The figure arises as a fold in the ground itself. 
something that has an existence of its own, and yet the crease is still in the sheet. It is not as though the sheet had parted company with the crease and sunk back into flat homogeneity, leaving the crease-line, as it were, high and dry (Ingold 2015: 34-5). So it is, too, with lines and the ground: the line, says Deleuze, distinguishes itself from the ground "without the ground distinguishing itself from the line" (Deleuze 1994: 29). The distinction, in short, is unilateral. Every distinguishing feature, then, is a fold in the ground (Figure 2).

My contention is that in a life of longing, all difference arises thus, from within, in the midst of things. It is, in that sense, interstitial. It follows that the life of the soul is to soul-life as the crease is to the sheet, or as the line is to the ground. As the crease distinguishes itself from the sheet or the line from the ground, so the particularity of the singular life distinguishes itself from the universality of life itself, without the universal's distinguishing itself from the particular. That is why I call the life process one of interstitial differentiation rather than of exterior articulation. As articulation is to differentiation, so is alliance to filiation, and assemblage to correspondence. Perhaps you might compare the distinction to that between cutting timber transversally with a saw and splitting it longitudinally with an axe.
The saw cuts the length into blocks or sections, which can only be reassembled through conjunction. But the axe joins with the timber, as in its swerve it corresponds with lines of growth that were incorporated into the wood when it was part of a living tree. The axe acts on the timber as the preposition on the noun, following the grain of the world's becoming and differentiating it from within (Figure 3).

\section{The self and the soul}

Now to us anthropologists, the ontology that gives us the ground of nature as a universal and homogeneous substrate upon which are set the fragmentary forms of cultural diversity will be immediately recognizable as the default position adopted by generations of textbooks - a position that tends to be glossed by such nonspecific words as "western" and "modern." Philippe Descola, in his treatise Beyond nature and culture (2013), calls it "naturalism." For Descola, naturalism is one of four logically possible ontological schemas that underwrite the way human beings can organize their relations with one another and with the world they inhabit, and render this world intelligible. The others are analogism, totemism, and animism. This is not the place for an

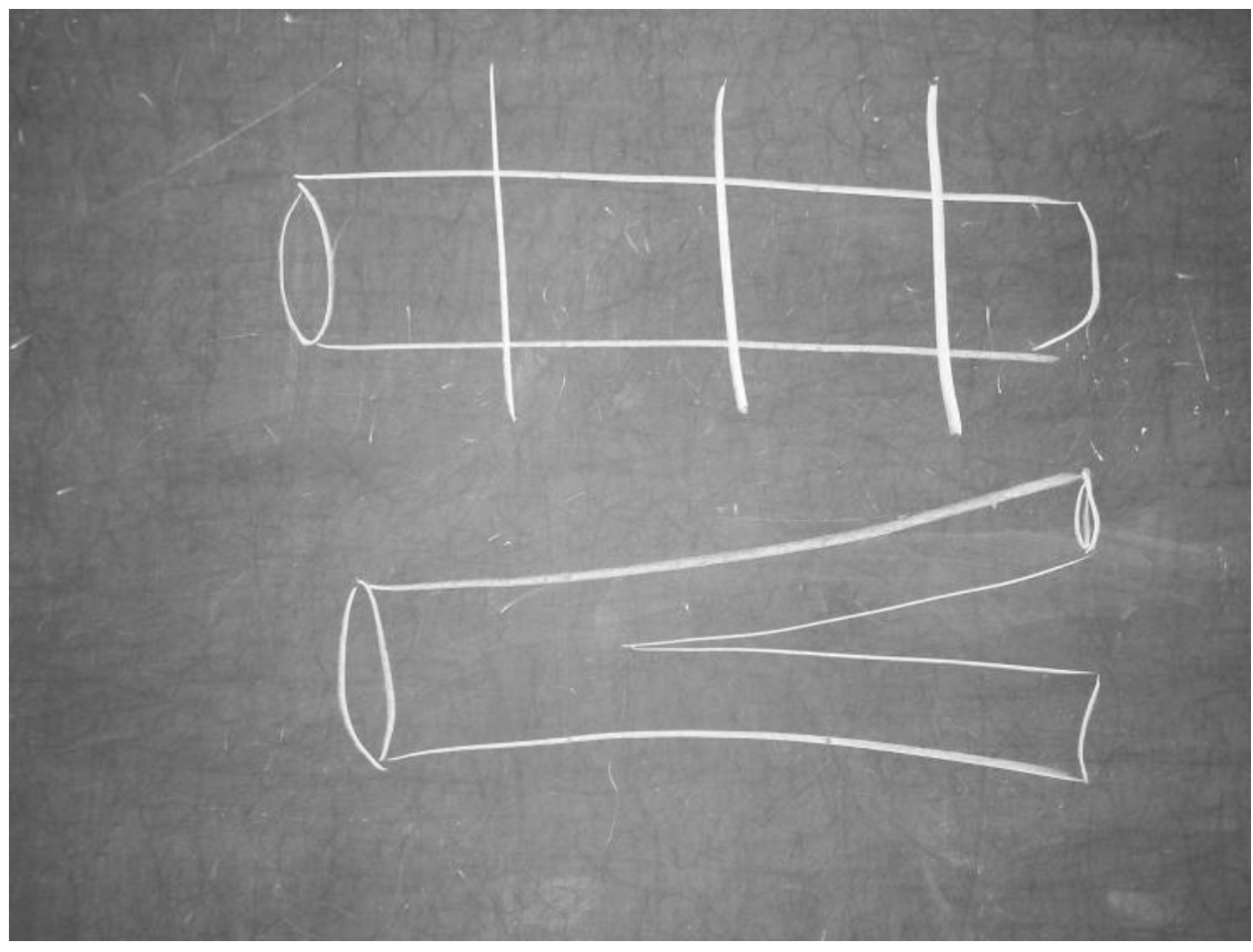

Figure 3: Transverse and longitudinal cut. Above: A log sawn against the grain into sections. Below: The same log split along the grain with an axe. 
extended review of Descola's arguments (see Ingold 2016). But I would like to attend briefly to his account of animism, since by doing so I can both add some precision to what I mean by the relation between the life of the soul and soul-life, and clarify the sense of "oneworld-ness" that follows from it.

There is one characteristic of animism, Descola assures us, that "everyone can accept," and this is the "attribution by humans to non-humans of an interiority identical to their own" (Descola 2013: 129). By this he means that plants and (especially) animals are taken to be endowed with souls which enable them to act, normatively and ethically, as social beings, just as humans do. Against this homogeneous sea of souls, common to all animate beings, there stands the diversity of exterior physical bodies that gives each particular soul its executive armature and allows it to function in the world in the particular way it does. In this regard, Descola thinks, animism is the perfect inverse of modern or western naturalism, which gives us the diversity of forms of mental or spiritual life (or what modern people call "cultures") set against the background of a homogeneous, physical nature. Or in a nutshell, whereas animism is the combination of similarity of interiorities and dissimilarity of physicalities, naturalism is the combination of similarity of physicalities and dissimilarity of interiorities.

Now this all sounds very neat, until you start to wonder why naturalism, in the same breath that it extols the universality of nature, vis-à-vis the diversity of cultures, also celebrates the boundless diversity of living kinds or species vis-à-vis the universality of the human mind and of its conscious sense of self. What is similar, and what is diverse, depends on which way you look! And if naturalism can just as well be defined by the dissimilarity of physicalities and similarity of interiorities as by its opposite, then how can it any longer be distinguished from animism? The answer, I think, is that compared with the similarities and dissimilarities of animism, those of naturalism are of another kind. In brief: naturalism's similarities are of identity, animism's are of continuity; naturalism's differences are of diversity, animism's are of differentiation. To amplify these twin distinctions, we can bring an earlier masterpiece of comparative anthropology, Roy Wagner's The invention of culture (1975), to our aid.

While for Descola, naturalism and animism are but two of four possible ontological schemas, Wagner offers only two possibilities. On the one hand are people who deliberately assemble life into collectivities, and in so doing precipitate an idea of the world as made up of primordially discrete, enumerable entities, otherwise known as individuals. On the other hand are people for whom the task is to differentiate life into separable streams, precipitating as they do so an idea of the world as primordially undifferentiated (Wagner 1975: 51). For Wagner these alternatives are exemplified respectively by "middle-class Americans" and the Daribi people of Papua New Guinea among whom he carried out his fieldwork: the former broadly representative of western modernity, the latter of "tribal peoples." Let us, for the sake of argument, gloss over the obvious problems with the terms of comparison, and allow the first to equate broadly to Descola's "naturalism," and the second to his "animism." What interests me here is not where Wagner draws his lines between the West and the rest, but what he has to say about the self and the soul under the two contrasting ontological regimes (1975: 93-4).

Under the first regime, of naturalism, similarity means identity. We imagine a world of individuals. These individuals can be counted. They can be aggregated into the kinds of collectivities we call "societies." And they can be compared according to their intrinsic attributes. An attribute is deemed to be universal when it is common to every entity; it is particular when it is limited to a narrower class of entities, or perhaps even unique to a single entity. Thus, we might claim that every individual human being possesses a sense of self, a singular seat of reason and conscience, and that this sense is therefore universal. But we might also claim that the mode of expression of this sense varies between one group of human beings and another, and class all those who express their selfhood in a certain way as members of one culture, and all those who express it in a different way as members of another. We would, in so doing, establish what we take to be the "fact" of cultural diversity, although - as Wagner shows - this "fact" is really just the precipitate of a logical procedure.

Under the second regime, of animism, we start not with populations of more or less identical individuals but with a continuum of yet-to-be differentiated relations. Out of this continuum, recognizable beings have to be formed. It is the task of life to do so. Yet in this process of formation, which carries on throughout life and is never complete, there always remains a memory of that undifferentiated potential from the interstices of which every being is drawn. This memory is the soul. In a sense, the soul is a constant reminder of the viscosity of the relational field, and of the effort that has to be put in to 
work against it. It is the reflex of life-as-a-whole that is coiled up into each part - into each particular life - in the course of that very differentiation by which the parts emerge from the whole. In this regard, the soul is the precise obverse of the self. Under a regime of naturalism, the self may be disciplined in the work of creating a collectivity, it may be forced to conform to common standards, and yet its very persistence attests to the threat of decomposition, reminding us that without continued effort, the whole is liable to collapse into its individual constituents. Under a regime of animism, by contrast, the soul cannot be disciplined, but it can be lost, drowned in the very ocean from which it was once generated (Wagner 1975: 98). Whereas the self casts its shadow on the inner walls of society, life-as-a-whole carries the soul in the midst of its involute folds.

\section{Into the vortex}

"Life in general," wrote the philosopher Henri Bergson in his Creative evolution (1911), "is mobility itself; particular manifestations of life accept this mobility reluctantly, and constantly lag behind" (1911: 128). Bergson pictured the particular life, thus, as a kind of eddy or whirlwind, a circulation, brought on by a swerve or deflection in the current of life itself that would otherwise proceed relentlessly on its rectilinear course. Life itself is an evolution; the cycle of every particular life is a revolution. The first, though it may be continuous with the second, "cannot continue in it without being drawn aside from its direction" (Bergson 1911: 129). There is much in common between Bergson's vitalism and the animism, described above, which casts the particular life as the life of the soul, and life itself as soul-life. We can, I think, take the one as a guide to the other. And in doing so we can see that in the world according to animism, things are never ready formed-never fully precipitated from the matrix of their generation - but ever-forming, as concentrations of vital materials and energies that are, and must remain, perpetually in circulation. Everything that is - or better, everything that occurs - is immersed in the flow.

Thus, it is all very well to speak, with Descola, of the interiority of soul-life, but this is not, as he would have it, an interiority set over and against the exteriority of bodies. It is rather the interiority of life that is immanent in the world itself, and that participates directly in its relations and processes. Let us follow Deleuze (2001) in calling this the interiority of immanence. Quite contrary to the interiority that is opposed to the physicality of the exterior world, the interiority of immanence runs seam- lessly into physicality, like the singular surface of a Möbius strip, without any breach of continuity. Recall Bergson's comparison of the life cycle to the eddy in a stream. Can you tell what is inside the eddy from what is outside? Of course not, for the eddy is not a container and it has no content. It is a vortex, the form of turbulence. As Bergson observed, though the life-form, like the eddy, might appear to us as a stable thing, with an inside and an outside, the appearance is deceptive, for in truth "the very permanence of ... form is only the outline of a movement" (1911: 128). Every particular soul, likewise, is but an eddy in the flow of soul-life, a vortex that continually winds and unwinds. It is a place not of rest but of tumult. Only at the eye of the vortex does stillness reign. Here's the philosopher Michel Serres, in The birth of physics (2000), baring his own soul: "I am myself a deviation, and my soul declines, my global body is open, adrift. It slips, irreversibly, on the slope. Who am I? A vortex" (Serres 2000: 37).

But if the differences of animism, manifesting on the plane of immanence, arise thus as singular vortices in the current, those of naturalism have broken off from it and lie strewn upon that plane of indifference otherwise known as "nature." The former are emergent and interstitial; the latter resultant and superficial. Whereas animism, then, gives us a world of becoming, naturalism gives us a world of being. And it is the logic of naturalism, operating from behind the scenes in Descola's account, which contrives to wrap every cycle of life into itself, thus converting the generative currents of its formation into a vital agent that is supposed to inhabit an interior divided off from the exterior world of its interactions with others (Figure 4). In my call for a one-world anthropology, I want to escape the deadening impact of this logic, to release the soul from its imagined incarceration and to restore its turbulence to the circulations of life. It is to appeal not to the naturalistic dyad of identity and diversity but to the animistic pairing of continuity and differentiation. The universal, then, is not a lowest common denominator but a field of continuous variation; not a plane of indifference upon which diversity is overlain, but a plane of immanence from which difference is everemergent.

\section{Agency and patiency}

The next stage in my argument is to relate the principle of interstitial differentiation to the problem of agency. I want to suggest that there is a connection between the question of how to reconcile the singular and the plu- 


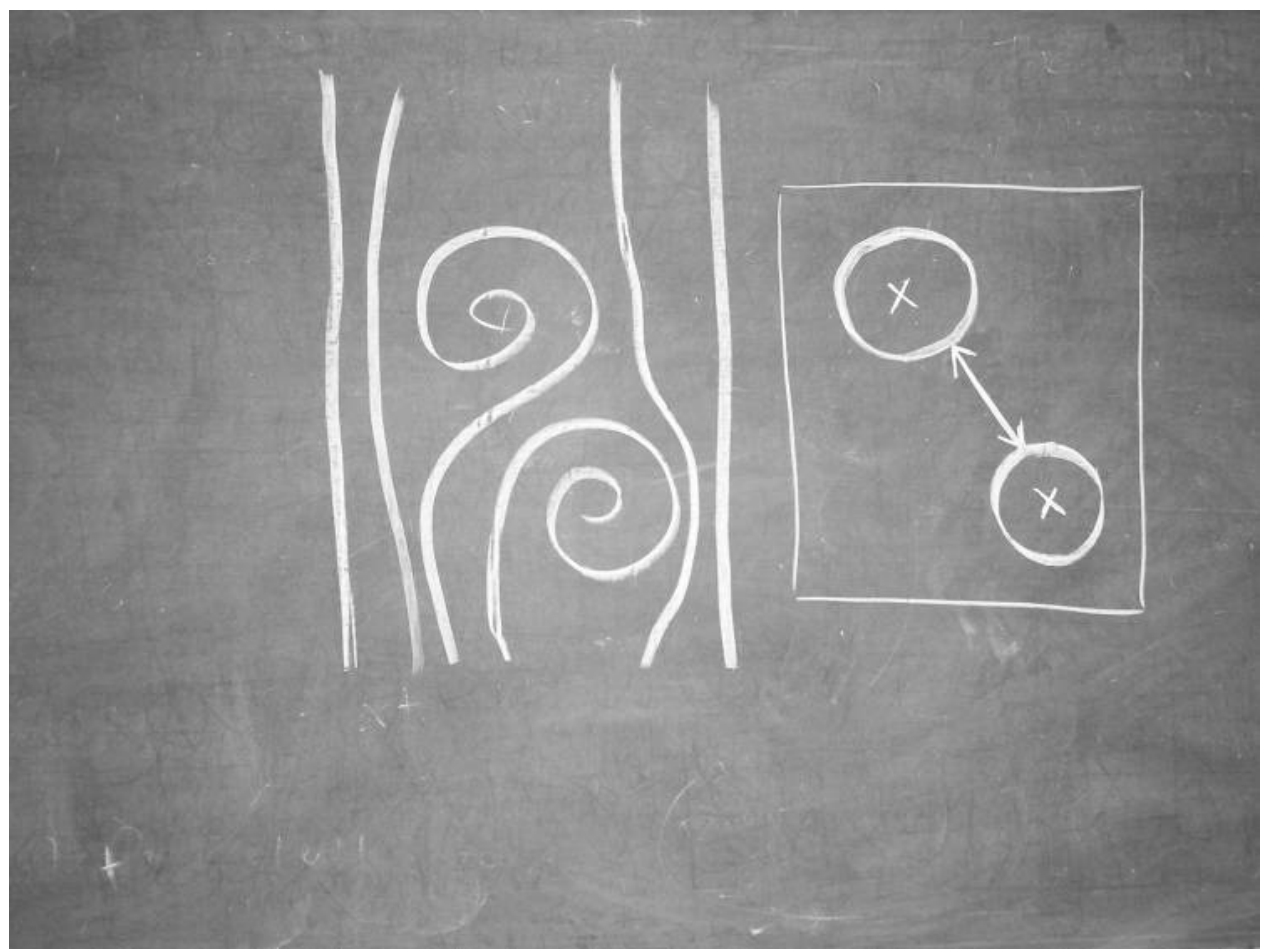

Figure 4: Wrapping the soul. Left: Souls emerge as vortices in the current of life. Right: They appear contained and interact only by way of their exterior bodies.

ral, and the life of the soul with soul-life, and the question of how to relate agency and patiency, action and suffering. Indeed, the connection is so intrinsic that these seem to me to be alternative ways of posing what is fundamentally the same problem. The life of the soul is made up of doings; soul-life, by contrast, is what a living being undergoes. So, our question is really about the relation between doing and undergoing. Now in the grammar of most modern Indo-European languages, there is a distinction between the active and passive voices of the verb: the active voice is for what one does; the passive for what one undergoes. Should we, then, think of life in the active voice or in the passive? Or should we think in terms of some kind of interplay between the two? More precisely, should the active be framed within the passive or vice versa? Are the things we do the callings of a life that happens to us, or are the things that happen to us called up by the things we do?

For those of us raised in an Indo-European linguistic environment, our usual habits of thought - conditioned as they are (though by no means determined) by the grammatical categories of the languages we speak - put the agency of the individual out in front, as the sovereign initiator of his or her actions, that is as a self. And this self stands opposed to the exterior environments of nature and society in which its actions have effects. Thus, we tend to set the agency of the particular life against the passive backdrop of life in general. The principle of interstitial differentiation, however, suggests that the doings of every particular life continually emerge and distinguish themselves from within the plane of immanence that is life itself. This is to frame doing within undergoing, and not the other way around. And it is to think of every doing not as self-initiated action but as a moment in the life of the soul. Such doings belong not to us directly or exclusively, but to the memory of the whole coiled up within us. Another way of putting this is to think of everything we do as a task. For the task is something that falls to us, as responsive and responsible beings, as part of the life we undergo. To revert to an earlier distinction, it is a way of corresponding with the world in which we live, rather than of interacting with it.

If every doing is a task, then we need to find a way of talking about agency that puts it inside undergoing. With our conventional dichotomy between active and 
passive voices of the verb, this is very difficult to do. However, many non-European languages (as well as Indo-European in earlier times, such as in classical Greek) recognized what linguists call the middle voice of the verb. In the middle voice, agency is inside the action, inside the verb. As the linguist Émile Benveniste put it, in a classic paper, in the middle voice the doer "achieves something that is being achieved in him" (1971: 149). My suggestion, then, is that in the one world of becoming, life is lived neither in the active nor in the passive but in the middle voice. Such is the life of the soul. Its particular life is not played out against the background of life itself but emerges actively from its midst. With life lived in the middle voice, our focus can no longer be on the essence of being. It is must rather be on its ongoing generation. That is to say, it should be not on ontology but on ontogeny.

This idea of ontogenesis (as ontogénèse, the "becoming of being") was key to the philosophy of Gilbert Simondon, for whom it equated more or less to the process he otherwise called individuation, that is, the continual "falling out" of being from becoming. "It corresponds," Simondon wrote, "to a capacity beings possess of falling out of step with themselves, of resolving themselves by the very act of falling out of step" (Simondon 1993: 300). There are echoes, here, of Bergson's idea that life "lags behind" in the deflections and circulations of its particular forms; that where life in general forges ahead, its cycles "want to mark time" (Bergson 1911: 128). In the process of individuation, we could say, the soul arises as a transient falling out-of-step, "a metastable being, which carries within itself the preindividual forces from which it was produced" (Grosz 2012: 41). As a kink, fold, or vortex in the flow of life, the soul nevertheless contains within itself, as a memory of the forces that produced it, the potential for further transformation. In Simondon's terms, life itself (or soul-life) is a never-ending process of individuation, but critically, the differentiations it engenders are concentrated not at some putative boundary with an outside world, but in its internal resonances (Simondon 1993: 305). Or in other words, life as individuation - as lived in the middle voice - is a process of interstitial differentiation.

\section{An ontogenetic turn?}

I do not like the idea of "turns"; they are, for the most part, exhibitions of academic vanity. But if we must have such things to indicate the transitions in our thinking, then let us follow Simondon in calling for a turn that is not ontological but ontogenetic. Let our concern be not with philosophies but with generations of being. With multiple ontologies, everything or every being is its own world, closed in and complete, so that ultimately there are as many worlds as there are beings or things. Each has collapsed into itself, ultimately impenetrable to others. This is the reductio ad absurdum of objectoriented ontology. But with multiple ontogenies, every being or thing is open, subject to growth and movement, issuing forth along its own particular path within a world of nevertheless unlimited differentiation. Nothing in this world is settled, once and for all. In short, ontogenesis allows us to reconcile singularity and multiplicity, agency and patiency, within one world.

"There is only one world," declares the philosopher Alain Badiou, but it is a world that refuses any normative preconditions for existing in it — such as might be entailed in any naturalistic definition of universal humanity (Badiou 2008: 38; see Trott 2011: 87). How many times have we attempted to define human nature in terms of the common possession of this or that attribute-bipedalism, tool-making, pair-bonding, language, symbolic thought, and so on-only to discover that there are creatures born of man and woman who lack these attributes and who consequently find themselves excluded, or at least considered less-than-human? The one world we inhabit is not, however, reserved for what anthropologist Donald Brown (1991) has called "Universal People," creatures of the normative imagination delineated by a suite of innate capacities and behavioral traits that all are supposed to share. It is rather a world of ever-emergent difference, which admits no boundaries of inclusion or exclusion.

In this world of becoming, as I have observed elsewhere, though each of us may be different, these differences are constituted in and through the generative processes of life; they do not exist in spite of it. To point to similarities, by contrast, is to imagine a world already fragmented into its minimal constituents. "In short, it is difference that connects, whereas similarity divides" (Ingold 1996: 6). Political theorist William Connolly makes much the same point, insisting that "there is no identity without difference." To pit the "universal" against "difference," Connolly writes, "reduces the essentially relational character of difference to the bland idea of diversity among independent entities" (Connolly 1995: xx, original emphasis). It is, as we 
have already seen, to reduce the differentiation of becoming to the diversity of being. To undo this reduction, we must put difference and the universal back together again. This is what Badiou does. "The single world," he argues, "is precisely the place where an unlimited set of differences exist . . . far from casting doubt on the unity of the world, these differences are its principle of existence" (Badiou 2008: 39). I believe that anthropology should be fighting, intellectually and politically, for the recognition of this kind of world. So what should we call it?

In 1908, the American philosopher William James delivered the Hibbert Lectures at the University of Oxford, published in the following year under the title $A$ pluralistic universe. James's proposed solution to the problem of the one and the many was to insist that the "multiverse," as he called it, is simultaneously both singular and plural for the reason that its one-ness is never absolutely complete. It is "strung-along," said James, "not rounded in and closed" (James [1909] 2012: 170). Regardless of the part or element on which you might choose to focus, at whatever level of exclusiveness of inclusiveness, there is always an overflow of relations. Wherever you are, there are further connections to be drawn, maybe direct, maybe through intermediaries. And in the drawing of these connections, even in their interpenetration, things lose nothing of their particularity.

Should we follow James and call our one world a multiverse or pluriverse, rather than a universe? Well, yes and no. We may agree with the geographer and environmental philosopher Augustin Berque, that the idea of the universe in its modern, naturalistic senseas an objective exteriority that can be grasped only by the interior mind of the transcendental subject- " negates all possibility of a world ... that is both supremely qualitative and totally unitary," that is, the kind of world posited by Plato in the final lines of the Timaeus with which I began this essay (Berque 2013: 51). Yet I would still want to enter one qualification, which goes back to my comparison of the conjunction and the preposition as ways of joining. The Jamesian pluralistic universe is multiply connected, yet its connections are conjunctive, not prepositional. They join things externally, on the outside. "Pragmatically interpreted," wrote James, "pluralism or the doctrine that it is many means only that the sundry parts of reality may be externally related. Everything you can think of, however vast or inclusive, has on the pluralistic view a genuinely 'external' environment of some sort or amount." This seems plain enough. Indeed, the Jamesian multiverse is rhizomatic in every way: it is "and . . and . . . and"; the very model of an assemblage. Yet the passage that immediately follows is more equivocal. "Things are 'with' one another in many ways," James goes on, "but nothing includes everything, or dominates over everything. The word 'and' trails along after every sentence. Something always escapes" (James [1909] 2012: 167). Notice how in this passage, James starts with "with" and only then resorts to "and." Perhaps he would have liked it both ways.

\section{Universe, fractiverse, pluriverse}

This dilemma has not gone away, nor has the question it raises. Is our world a patchwork of multiple realities, irregularly stitched across their rough, unmatched, and sometimes overlapping edges? Or is it more like a braid: a thing of entwined and ever-extending pathways, binding longitudinally rather than transversally along their lines of growth and movement? Writing from his perspective as a student of science and technology, John Law (2011) has recently presented an answer of the first kind. His concern is to offer an alternative to the idea that everything there is can be made to fit into a single container universe, or what he calls the "one-world world" (Law 2011: 10). In such a world, anything that cannot be made to fit - anything that flies in the face of universal reality - is simply dismissed as an instance of belief, and mistaken belief at that. In a world divided between colonized and colonizers, what the former take for truth is classed by the latter as mere belief, though as Law shows, the same logic has long been at work in the societies of the colonizers as well. But it is a logic that fails in a post-colonial era, in which different and incommensurable realities grind against one another with no assurance of reconciliation or containment. We now live, says Law, in the era of the fractiverse, "a set of contingent, enacted and more or less intersecting worlds in the plural" (2011: 2).

Worlds in the plural? We seem to be back where we started, with the many as opposed to the one. Perhaps this is because of Law's focus on the being of things rather than their becoming, on ontologies rather than ontogenies. The realities, multiple as they are, seem in Law's account to have already fallen out from the matrices of their generation. To recover the one-ness of the world, should we not move upstream, and correspond with things in the moment of their appearing, rather than assembling what has already appeared on 
the conjunctive hook of an and? This is, in effect, to seek an answer of the second kind. Returning to the philosophy of James, but in the context of contemporary geopolitics, anthropologist Arturo Escobar (2011) hints at just such an answer. For Escobar the one-world world is the globe of corporate capitalism. Epitomized in the celebrated logo of the World Bank-with its perfect gridlocked sphere shorn of life, elements, and peoplethis is indeed a world that is "rounded in and closed," as James would have put it, and in which everything there is has been reduced to liquid commensurability. It is a world of commodities and monetary values, from which people are overwhelmingly marginalized if not actually locked out (Badiou 2008: 38).

Against this global world, and with acknowledgment to James, Escobar reintroduces what he calls the pluriverse. "It might be described," he writes, "as a process of planetarization articulated around a vision of the Earth as a living whole that is always emerging out of the manifold biophysical, human, and spiritual elements and relations that make it up" (Escobar 2011: 139). Unlike Law's fractiverse, Escobar's pluriverse is unambiguously "with . . . with . . . with." It is prepositional, not conjunctive, and its plurality arises not from chains of exterior connection — of things strung along — but from the cascades of individuation or interstitial differentiation by which the "Earth as a living whole"- to borrow Escobar's words - is continually emerging. It is to the one-worldness of this whole, I believe, that anthropology must remain committed.

Yet for this very reason, I have my doubts about the propensity of anthropological scholarship always to want to put other lives within their social, cultural, and historical contexts. This is like laying them to rest, putting them to bed, so that we need no longer engage with them directly. Embedding lives in context implies an already completed conversation. It is as though they are no longer enjoined in the world we inhabit but rather set aside as the objects of our concern. They belong to other worlds, not to ours. If we are to return these lives to our one world, then we must recall them from the contexts in which our scholarship has buried them, and bring them back into presence. We will then discover that what we had closed off embraces all we should acknowledge.

As I stated at the outset, the world is a conversation; it is not the object of our conversation. In this conversation lies ontogénèse, the becoming of being. It is high time to restore ontogenesis, the skeleton in the ontological cupboard, to life. We will then see that every particular life is both an open-ended exploration of the possibilities of being our one world affords and a contribution to its ongoing formation - to its worlding. It is, in this sense, a never-ending quest for an answer to the problem of what being human, or what living in this world, actually means. But every answer is a response and not a solution: a response that "provisionally integrates what was formerly a source of tension" (Grosz 2012: 39). Responding to the question, we respond to one another; that is, we correspond. And in this, we do not so much look out from a position as long for one that is forever beyond our grasp. Life is a question to which there is no answer, but in this one world of ours we are all tasked with looking for it, and it is in the search that all life is lived. And it is just as well that there is no final solution, for that, indeed, would put an end to us all.

\section{Acknowledgments}

I first presented a preliminary sketch for this paper at the conference The Human Condition: Reinventing Philosophical Anthropology at the Institute of Advanced Studies, University of Aarhus, in June 2015. The first written version was presented as a seminar at the Department of Anthropology, McGill University, the following October. Since then the paper has continued to evolve, with presentations to the Creation of Reality Group conference at the University of Edinburgh in December 2015, as the J. J. Bachofen Lecture at the University of Basel in March 2016, and a month later as the 2016 inaugural lecture for the Anthropology Programme at the Catholic University of Chile, Santiago. In September 2016 I presented a version of the paper under the title "An Ecology of Life" at the Centre for Contemporary Culture of Barcelona, as part of the 2nd International Conference of the Network of Iberoamerican Anthropologists (AIBR), and again in October 2016 at the School of Humanistic Studies of the University of Bologna. I have thoroughly revised the paper for each occasion. I would like to thank the European Research Council for the award of an Advanced Grant (323677-KFI, 2013-18) that released me from other obligations to work on the paper, and the audience on every occasion of its presentation for much tremendously helpful feedback, without which it would never have progressed in the way it has. For any remaining shortcomings, which I am sure are many, I accept full responsibility.

\section{References}

Archer-Hind, Richard Dacre, ed. 1888. The Timaeus of Plato. London: Macmillan. 
Badiou, Alain. 2008. “The Communist hypothesis." New Left Review 49: 29-42.

Benveniste, Émile. 1971. "Active and middle voice in the verb” (1950). In Problems in general linguistics, by Émile Benveniste. Translated by Mary Elizabeth Meek, 145-51. Coral Gables, FL: University of Miami Press.

Bergson, Henri. 1911. Creative evolution. Translated by Arthur Mitchell. New York: Henry Holt.

Berque, Augustin. 2013. Thinking through landscape. Translated by Anne-Marie Feenberg-Dibon. London: Routledge.

Brown, Donald E. 1991. Human universals. New York: McGraw-Hill.

Connolly, William E. 1995. The ethos of pluralization. Minneapolis: University of Minnesota Press.

DeLanda, Manuel. 2006. A new philosophy of society: Assemblage theory and social complexity. London: Continuum.

Deleuze, Gilles. 1994. Difference and repetition. Translated by Paul Patton. New York: Columbia University Press.

2001. Pure immanence: Essays on a life. Translated by Anne Boyman. New York: Urzone.

Deleuze, Gilles and Félix Guattari. 2004. A thousand plateaus: Capitalism and schizophrenia. Translated by Brian Massumi. London: Continuum.

Descola, Philippe. 2013. Beyond nature and culture. Translated by Janet Lloyd. Chicago: University of Chicago Press.

Escobar, Arturo. 2011. "Sustainability: Design for the pluriverse." Development 54 (2): 137-40.

Gibson, James J. 1979. The ecological approach to visual perception. Boston: Houghton Mifflin.

Grosz, Elizabeth. 2012. "Identity and individuation: Some feminist reflections." In Gilbert Simondon: Being and technology, edited by Arne de Boever, Alex Murray, Jon Roffe, and Ashley Woodward, 37-56. Edinburgh: Edinburgh University Press.

Harman, Graham. 2011. "The road to objects." Continent 3 (1): 171-79.

Ingold, Tim. 1992. “Editorial.” Man (N.S.) 27 (4): 693-96.

. 1993. "The temporality of the landscape." World Archaeology 25 (2): 152-74.

1996. "Introduction." In Key debates in anthropology, edited by Tim Ingold, 1-14. London: Routledge.

. 2007. "Movement, knowledge and description." In Holistic anthropology: Emergence and convergence, edited by David Parkin and Stanley Ulijaszek, 194-211. Oxford: Berghahn.

2015. The life of lines. Abingdon: Routledge.

2016. "A naturalist abroad in the museum of ontology: Philip Descola's Beyond nature and culture." Anthropological Forum 26 (3): 301-20.

James, William. (1909) 2012. A pluralistic universe. Auckland, NZ: The Floating Press.

Latour, Bruno. 2010. "An attempt at writing a compositionist manifesto." New Literary History 41 (3): 47190 .

Law, John. 2011. "What's wrong with a one-world world." Paper presented to the Center for the Humanities, Wesleyan University, Middletown, Connecticut, September 19, 2011. http://www.heterogeneities.net/publications /Law2011WhatsWrongWithAOneWorldWorld.pdf.

Masschelein, Jan. 2010. "The idea of critical e-ducational research-e-ducating the gaze and inviting to go walking." In The possibility/impossibility of a new critical language of education, edited by Ilan Gur-Ze'ev, 275-91. Rotterdam: Sense Publishers.

Nuttall, Mark. 1994. "The name never dies: Greenland Inuit ideas of the person." In Amerindian rebirth: Reincarnation belief among North American Indians and Inuit, edited by Antonia C. Mills and Richard Slobodin, 123-35. Toronto: University of Toronto Press.

Schutz, Alfred. 1962. The problem of social reality (Collected Papers I), edited by Maurice Natanson. The Hague: Nijhoff.

Scott, Colin. 1989. "Knowledge construction among Cree hunters: Metaphors and literal understanding." Journal de la Société des Americanistes 75: 193-208.

Serres, Michel. 2000. The birth of physics. Translated by Jack Hawkes. Manchester: Clinamen Press.

Simondon, Gilbert. 1993. "The genesis of the individual." In Incorporations, edited by Jonathan Crary and Sanford Kwinter, 297-317. New York: Zone.

Stanner, William E. H. 1965. "The dreaming." In Reader in comparative religion, edited by William A. Lessa and Evon Z. Vogt, 269-77. New York: Harper \& Row.

Stewart, Henry. 2002. "Ethnonyms and images: Genesis of the 'Inuit' and image manipulation." In Self- and otherimages of hunter-gatherers, edited by Henry Stewart, Alan Barnard, and Keiichi Omura (Senri Ethnological Studies 10), 85-100. Osaka: National Museum of Ethnology. 
Suzuki, Tadashi. 1986. The way of acting: The theatre writings of Tadashi Suzuki. Translated by J. Thomas Rimer. New York: Theatre Communications Group.

Trott, Adriel M. 2011. "The truth of politics in Alain Badiou: 'There is only one world'." Parrhesia 12: 82-93.
Wagner, Roy. 1975. The invention of culture. Englewood Cliffs, NJ: Prentice-Hall.

Wentzer, Thomas Schwarz. 2014. "II have seen Königsberg burning': Philosophical anthropology and the responsiveness of historical experience." Anthropological Theory 14: 27-48.

Tim Ingold is Professor of Social Anthropology at the University of Aberdeen, and a Fellow of the British Academy and the Royal Society of Edinburgh. He has carried out fieldwork among Saami and Finnish people in Lapland, and has written on environment, technology and social organization in the circumpolar North, the role of animals in human society, issues in human ecology, and evolutionary theory in anthropology, biology, and history. In more recent work, he has explored the links between environmental perception and skilled practice, on the interface between anthropology, art and architecture, and design. He is the author of The perception of the environment (2000), Lines (2007), Being alive (2011), Making (2013), The life of lines (2015) and Anthropology and/as education (2017).

Tim Ingold Department of Anthropology School of Social Science University of Aberdeen Aberdeen AB24 3QY Scotland, UK tim.ingold@abdn.ac.uk 